\title{
Miocarditis aguda eosinofílica como presentación inicial de una vasculitis
}

\author{
Acute eosinophilic miocarditis as debut of a vasculitis \\ Alejandro Junco-Vicente ${ }^{1 *}$, Luis Caminal-Montero ${ }^{2}$ y José Rozado-Castaño ${ }^{1}$ \\ ${ }^{1}$ Servicio de Cardiología; ${ }^{2}$ Unidad de Enfermedades Autoinmunes Sistémicas de Medicina Interna. Hospital Universitario Central de Asturias, Oviedo, \\ España
}

Mujer de 47 años con antecedente de asma, que consultó por dolor centrotorácico pleuropericardítico en situación de choque cardiogénico con marcadores de daño miocárdico elevados y disfunción sistólica moderada por hipocinesia global de ventrículo izquierdo, hipertrofia concéntrica moderada y sin alteraciones de la contractilidad segmentaria en el ecocardiograma. Tras recibir soporte hemodinámico, se consiguió su estabilización, descartándose enfermedad coronaria mediante tomografía computarizada de arterias coronarias. En días posteriores tuvo mejoría del cuadro de insuficiencia cardiaca aguda, pero persistió un marcado síndrome general. Las serologías para virus resultaron negativas. Se detectó una marcada y creciente eosinofilia periférica y anticuerpos anticitoplasma de neutrófilos-mieloperoxidasa positivos. Con la sospecha de una miocarditis se realizó una resonancia magnética cardiaca (Fig. 1 A, B, E y F) que confirmó el diagnóstico de miocarditis aguda. Ante los hallazgos y la sospecha clínica de un cuadro sistémico se procedió a realizar una biopsia endomiocárdica (BEM), que demostró una infiltración marcada de eosinófilos (Fig. 2 A y B). Todo ello confirmó el diagnóstico de una miocarditis aguda eosinofílica como presentación inicial de una vasculitis sistémica tipo poliangeítis granulomatosa eosinofílica (antiguo síndrome de Churg-Strauss). Se instauró tratamiento corticoideo intravenoso a altas dosis, con mejoría completa de la paciente, pasando posteriormente a dosis de mantenimiento en su domicilio. Al tercer mes en la consulta de revisión se encontraba asintomática con normalización de eosinofilia en sangre periférica y la resonancia cardiaca de control mostraba la resolución del cuadro sin secuelas (Fig. $1 \mathrm{C}, \mathrm{D}, \mathrm{G}$ y H). La miocarditis es una entidad grave, siendo la mayoría de origen vírico, pero existen otras etiologías menos frecuentes que no deberían olvidarse dentro del diagnóstico diferencial. Destacamos la miocarditis eosinofílica, que precisa de confirmación histológica mediante BEM. Su presentación clínica es variable, desde casos paucisintomáticos hasta formas fulminantes (Ilamada miocarditis eosinofílica necrotizante). De forma general asocia síntomas de insuficiencia cardiaca y síndrome coronario agudo, ya que los eosinófilos generan necrosis aguda de miocardiocitos. Es una entidad extremadamente infrecuente y de alta mortalidad, siendo determinante el diagnóstico y tratamiento precoz para mejorar su pronóstico.

\section{Financiamiento}

Ninguno.

\section{Conflicto de intereses}

Lo autores declaran no tener ningún conflicto de intereses.

\section{Correspondencia:}

*Alejandro Junco-Vicente

E-mail: ajuncovicente@ gmail.com
Disponible en internet: 23-02-2021 Arch Cardiol Mex. 2021;91(1):121-122 www.archivoscardiologia.com

1405-9940 / @ 2020 Instituto Nacional de Cardiología Ignacio Chávez. Publicado por Permanyer. Este es un artículo open access bajo la licencia CC BY-NC-ND (http://creativecommons.org/licenses/by-nc-nd/4.0/).

Fecha de recepción: 11-12-2019 Fecha de aceptación: 25-05-2020 DOI: 10.24875/ACM.20000393 


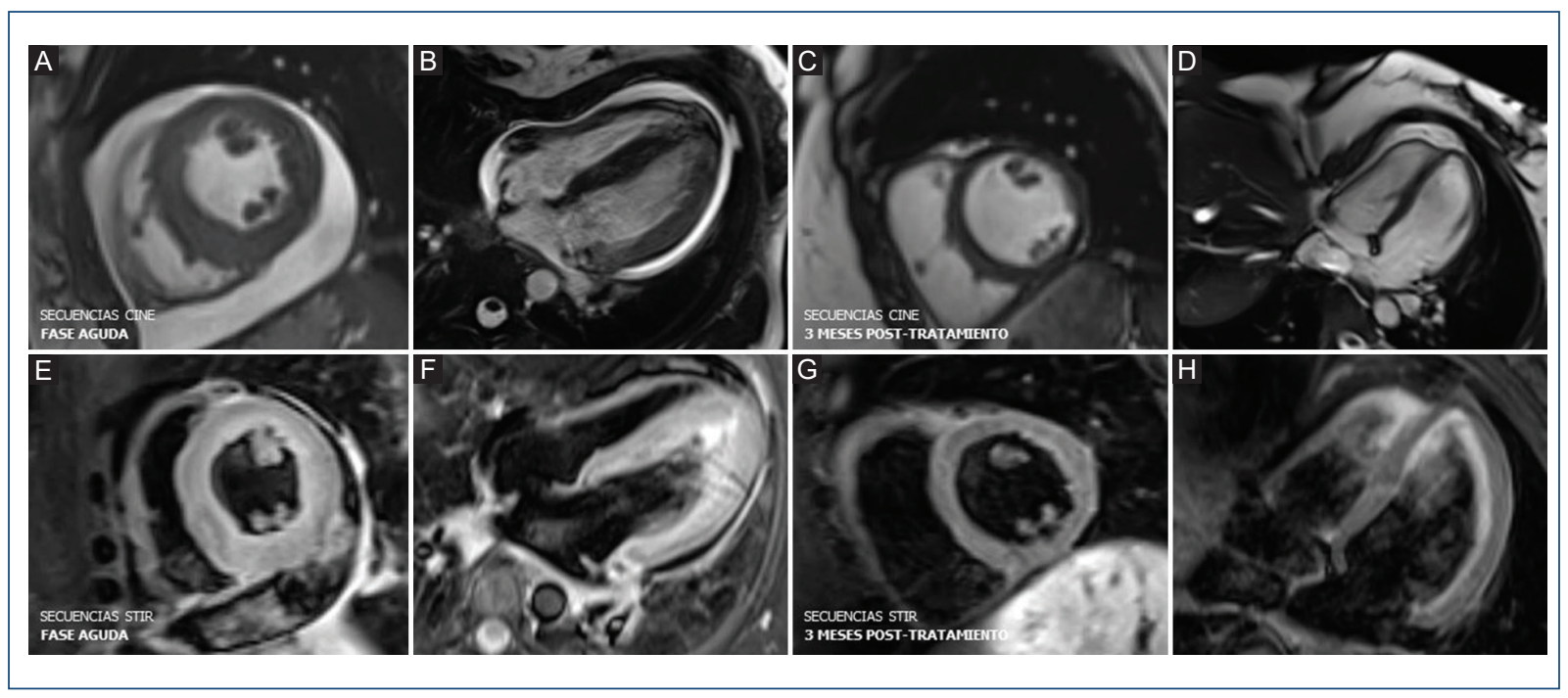

Figura 1. Resonancia magnética cardiaca. Estudio basal en fase aguda del cuadro clínico, donde se muestra en la secuencia CINE (A: Eje corto a nivel medioventricular y B: 4 cámaras), que muestra hipertrofia ventricular concéntrica, así como derrame pericárdico circunferencial. En las secuencias potenciadas en T2 (STIR); C y D: Secuencias CINE con mejoría relevante, disminuyendo la hipertrofia ventricular concéntrica con persistencia de leve derrame pericárdico circunferencial; E y F: Se observa hiperintensidad marcada (cociente T2 > 2) sugestiva de edema miocárdico difuso. Estudio tras tres meses de tratamiento con esteroides; $\mathbf{G}$ y H: Mejorando también el edema miocárdico, sin objetivar hiperintensidad en las secuencias potenciadas en T2.

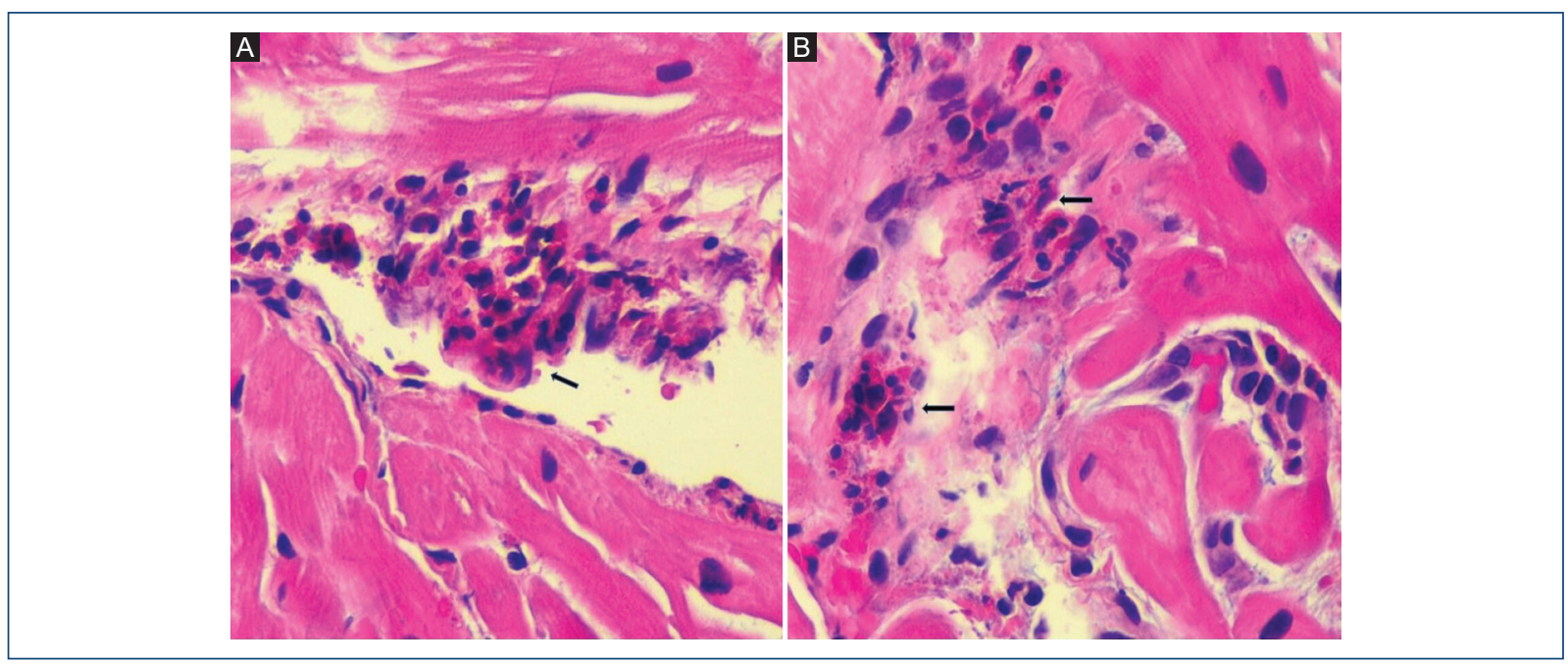

Figura 2. Imágenes histológicas de microscopia óptica (x40 aumentos) con tinción de hematoxilina-eosina procedentes de biopsia endomiocárdica. A: Se objetiva infiltración marcada de eosinófilos con edema intersticial (flechas negras) a nivel perivascular y $\mathbf{B}$ : Entre las fibras miocárdicas.

\section{Responsabilidades éticas}

Protección de personas y animales. Los autores declaran que para esta investigación no se han realizado experimentos en seres humanos ni en animales.
Confidencialidad de los datos. Los autores declaran que en este artículo no aparecen datos de pacientes.

Derecho a la privacidad y consentimiento informado. Los autores declaran que en este artículo no aparecen datos de pacientes. 